\title{
ESTIMASI GERAK SURGE, HEAVE DAN PITCH AUTONOMOUS UNDERWATER VEHICLE DENGAN ENSEMBLE KALMAN FILTER (ENKF)
}

\author{
Teguh Herlambang ${ }^{1}$, Subchan $^{2}$, Hendro Nurhadi $^{3}$ \\ ${ }^{1}$ Sistem Informasi, Fakultas Teknik \\ Universitas Nahdlatul Ulama Surabaya, Indonesia \\ e-mail: teguh@unusa.ac.id
}

\author{
2Departemen Matematika, Fakultas Matematika, Komputasi dan Sains Data \\ Institut Teknologi Sepuluh Nopember, Indonesia \\ e-mail: subchan@matematika.its.ac.id \\ ${ }^{3}$ Departemen Teknik Mesin Industri, Fakultas Vokasi \\ Institut Teknologi Sepuluh Nopember, Indonesia \\ e-mail: hdnurhadi@me.its.ac.id
}

Diterima: 3 April 2019. Disetujui : 15 Juni 2019. Dipublikasikan : 30 Juni 2019

(C)2019 -TESJ Fakultas Teknik Universitas Maarif Hasyim Latif. Ini adalah artikel dengan akses terbuka di bawah lisensi CC BY 4.0 (https://creativecommons.org/licenses/by/4.0/)

\begin{abstract}
ABSTRAK
Autonomous Underwater Vehicle (AUV) atau wahan air tanpa awak merupakan salah satu jenis robot bawah air yang relatif flexibel untuk eksplorasi bawah laut dan peralatan sistem pertahanan bawah laut. AUV dapat dikendalikan untuk bergerak dengan enam derajat kebebasan (6-DOF). Pengendalian AUV dibagi menjadi dua yaitu kendali kecepatan dan kendali agar mengikuti lintasan yang diinginkan. Kendali AUV agar mengikuti trajectory yang diinginkan ini biasa disebut dengan sistem navigasi atau Estimasi trajectory. Pada penelitian ini dikembangkan sistem navigasi untuk gerak menyelam dengan model 3DOF yaitu gerak surge, heave dan pitch dengan metode Ensemble Kalman Filter (EnKF). Hasil simulasi menunjukkan bahwa metode EnKF dapat digunakan sebagai estimator gerak 3-DOF dengan menghasilkan error $0.011 \mathrm{~m} / \mathrm{s}$ untuk gerak surge dan $0.009 \mathrm{~m} / \mathrm{s}$ untuk gerak heave serta $0.004 \mathrm{rad} / \mathrm{s}$ untuk gerak pitch, sedangkan error posisi menyelam $0.01 \mathrm{~m}$.
\end{abstract}

Kata kunci: AUV, Estimasi Posisi Menyelam, Sistem Navigasi, Ensemble Kalman Filter

\section{PENDAHULUAN}

Penelitian terkait AUV dikembangkan dalam rangka pemenuhan sistem pertahanan dan keamanan NKRI. Beberapa Penelitian dan Pengembangan AUV cukup banyak diantaranya terkait sistem kendali dan sistem navigasi guidance (T. Herlambang, Nurhadi, \& Subchan, 2014). AUV dalam bergerak harus sesuai lintasan yang diinginkan sehingga memerlukan sistem navigasi untuk mengestimasi gerak dan lintasan yang akan dilalui (T. Herlambang, Djatmiko, \& Nurhadi, 2016). AUV terdiri dari 6-DOF yang merupakan kombinasi dari gerak translasi (3-DOF) dan rotasi (3-DOF) (Oktafianto, Herlambang, Mardlijah, \& Nurhadi, 2016).

Beberapa penelitian terkait sistem navigasi diantaranya adalah Loebis dkk menjelaskan tentang sistem navigasi akustik dan kompas dengan metode Extended Kalman Filter (EKF) dan Simple Kalman Filter (SKF) pada Hammerhead AUV
(Loebis et al., 2004). Selanjutnya Panish dan Taylor (2011) menggunakan sistem navigasi pada Bluefin AUV dengan metode Inertial Navigation System (INS) (Panish \& Taylor, 2011). Pada tahun 2012, Motwani menggunakan Interval Kalman Filter pada AUV (Motwani, 2012). Pada tahun 2015, Ermayanti dkk menggunakan Fuzzy Kalman Filter (FKF) pada Segorogeni AUV (Ermayanti, Apriliani, Nurhadi, \& Herlambang, 2016).

Diantara metode-metode di atas, terdapat salah satu metode yang dapat digunakan untuk estimasi gerak AUV, adalah metode Ensemble Kalman Filter (EnKF). Metode EnKF digunakan untuk estimasi saham suatu perusahaan (Karya, Katias, \& Herlambang, 2018) estimasi lintasan misil (Teguh Herlambang, 2017), selain itu juga untuk estimasi water level steam drum boiler (Teguh Herlambang, Mufarrikoh, Karya, \& Rahmalia, 2018). Sehingga pada penelitian ini menggunakan metode Ensemble Kalman Filter 
(EnKF) untuk estimasi gerak menyelam dari ITSUNUSA AUV.

\section{METODE PENELITIAN}

\section{Autonomous Underwater Vehicle}

Untuk menganalisa sistem AUV terdapat dua hal penting yang diperlukan, yaitu sistem sumbu yang terdiri dari Earth Fixed Frame (EFF) dan Body Fixed Frame (BFF) (Herlambang and Nurhadi, 2017). Pada penelitian ini menggunakan persamaan gerak menyelam dalam 3-DOF yaitu surge, heave dan pitch dengan mengabaikan gerak rotasi yaitu sway, roll dan yaw. Berikut adalah persamaan gerak dalam 3-DOF:

$$
\begin{aligned}
& \text { Surge: } \\
& \dot{u}=\frac{\begin{array}{c}
X_{\text {res }}+X_{|u| u} u|u|+X_{w q} w q+X_{q q} q q+X_{\text {prop }}- \\
m\left[w q-x_{G}\left(q^{2}\right)+z_{G}(\dot{q})\right]
\end{array}}{m-X_{\dot{u}}}
\end{aligned}
$$

Heave :

$$
\dot{w}=\frac{\begin{array}{c}
Z_{\text {res }}+Z_{|w| w} w|w|+Z_{q|q|} q|q|+Z_{\dot{q}} \dot{q}+Z_{u q} u q+Z_{u w} u w+Z_{u u \delta_{S}} u^{2} \delta_{S^{-}} \\
m\left[-u q-z_{G}\left(q^{2}\right)+x_{G}(-\dot{q})\right]
\end{array}}{m-Z_{\dot{w}}}
$$

Pitch:

$$
\dot{q}=\frac{\begin{array}{c}
M_{\text {res }}+M_{w|w|} w|w|+M_{q|q|} q|q|+M_{\dot{w}} \dot{w}+M_{u q} u q+ \\
M_{u w} u w+M_{u u \delta_{s}} u^{2} \delta_{s}-\left(m\left[\begin{array}{c}
z_{G}(\dot{u}+w q) \\
-x_{G}(\dot{w}-u q)
\end{array}\right]\right)
\end{array}}{I_{y}-M_{\dot{q}}}
$$

Berikut adalah profil dan spesifikasi dari ITSUNUSA AUV pada Gambar 1 dan Tabel 1.

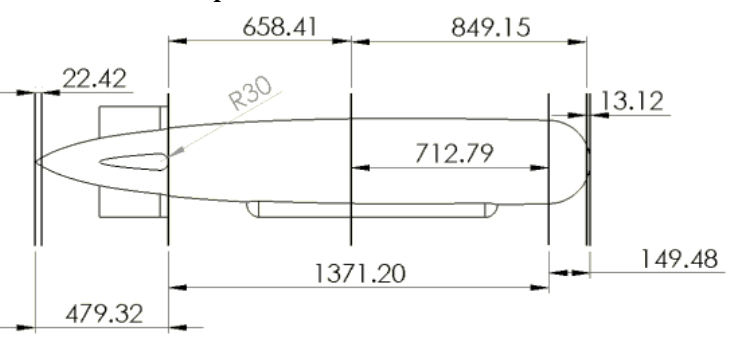

Gambar 1. Profil dari ITSUNUSA AUV (Teguh Herlambang \& Subchan, 2018)

Tabel 1. Spesifikasi dari ITSUNUSA AUV (Teguh Herlambang \& Nurhadi, n.d.)

\begin{tabular}{|l|l|}
\hline Weight & $16 \mathrm{Kg}$ \\
Overall Length & $2000 \mathrm{~mm}$ \\
Beam & $300 \mathrm{~mm}$ \\
Controller & Ardupilot Mega 2.0 \\
Communication & Wireless Xbee $2.4 \mathrm{GHz}$ \\
Camera & TTL Camera \\
Battery & Li-Pro 11,8 V \\
Propulsion & 12V motor DC \\
Propeller & 3 Blades OD : $40 \mathrm{~mm}$ \\
Speed & 1,94 knots $(1 \mathrm{~m} / \mathrm{s})$ \\
Operation Depth & $8 \mathrm{~m}$ \\
\hline
\end{tabular}

\section{Ensemble Kalman Filter}

Algoritma Ensemble Kalman Filter adalah sebagai berikut (T. Herlambang, Djatmiko, \& Nurhadi, 2015) :

Model Sistem dan Model Pengukuran

$$
\begin{gathered}
x_{k+1}=f\left(x_{k}, u_{k}\right)+w_{k} \\
z_{k}=H x_{k}+v_{k} \\
w_{k} \sim N\left(0, Q_{k}\right), v_{k} \sim N\left(0, R_{k}\right)
\end{gathered}
$$

1. Inisialisasi

Bangkitkan $N$ ensemble sesuai estimasi awal $\bar{x}_{0}$ dengan $x_{0, i}=\left[\begin{array}{llll}x_{0,1} & x_{0,2} & \ldots & x_{0, N}\end{array}\right]$

Tentukan nilai awal :

$$
\hat{x}_{0}=\frac{1}{N} \sum_{i=1}^{N} x_{0, i}
$$

2. Tahap Prediksi

$$
\hat{x}_{k, i}^{-}=f\left(\hat{x}_{k,-1, i}, u_{k-1, i}\right)+w_{k, i}
$$

dengan $w_{k, i}=N\left(0, Q_{k}\right)$

Estimasi :

$$
\hat{x}_{k}^{-}=\frac{1}{N} \sum_{i=1}^{N} \hat{x}_{k, i}^{-}
$$

Kovarian Error :

$$
P_{k}^{-}=\frac{1}{N-1} \sum_{i=1}^{N}\left(\hat{x}_{k, i}^{-}-\hat{x}_{k}^{-}\right)\left(\hat{x}_{k, i}^{-}-\hat{x}_{k}^{-}\right)^{T}
$$

3. Tahap koreksi

$$
\begin{gathered}
z_{k, i}=H x_{k, i}+v_{k, i} \\
\text { dengan } v_{k, i} \sim N\left(0, R_{k}\right) \\
\text { Kalman gain : } \\
K_{k}=P_{k}^{-} H^{T}\left(H P_{k}^{-} H^{T}+R_{k}\right)^{-1} \\
\text { Estimasi : } \\
\hat{x}_{k, i}=\hat{x}_{k, i}^{-}+K_{k}\left(z_{k, i}-H \hat{x}_{k, i}^{-}\right) \\
\hat{x}_{k}=\frac{1}{N} \sum_{i=1}^{N} \hat{x}_{k, i}
\end{gathered}
$$

Kovarian error :

$$
P_{k}=\left[I-K_{k} H\right] P_{k}^{-}
$$

\section{HASIL DAN PEMBAHASAN}

Pada penelitian ini estimasi gerak $t$ menyelam waha air tanpa awak atau AUV menggunakan metode Ensemble Kalman Filter (EnKF) dengan membangkitkan 200 dan 300 ensemble. Simulasi ini menggunakan $\Delta t=0,1$ serta dengan membangkitkan ensemble 200 dan 300 ensemble. Titik awal yang diberikan pada setiap lintasan $u(0)=0, w(0)=0$ dan $q(0)=0$. Gambar 2 sampai Gambar 4 adalah hasil simulasi estimasi gerak surge, heave dan pitch pada AUV, dimana gerak surge adalah gerak maju searah dengan sumbu- $x$ dan gerak heave adalah naik dan turun searah dengan sumbu- $z$ dan gerak Pitch adalah gerak rotasi naik dan turun yang searah sumbu-z. 


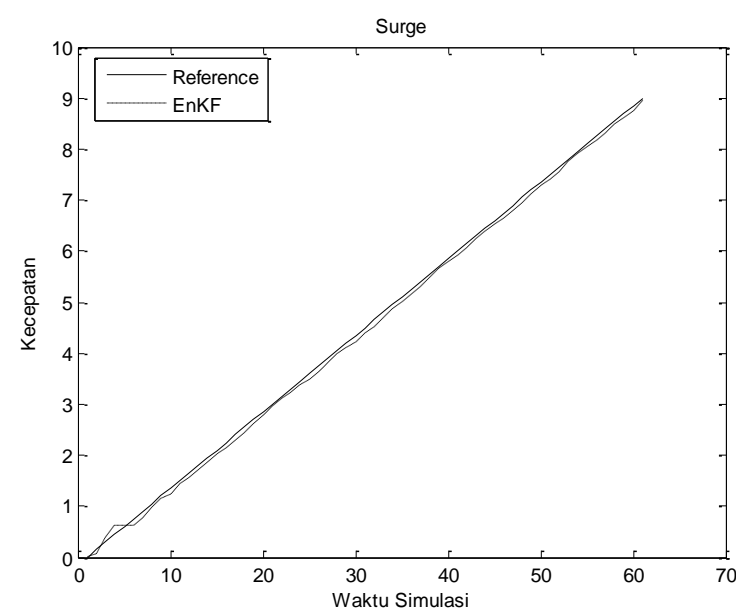

Gambar 2. Estimasi gerak dengan membangkitkan 200 Ensemble

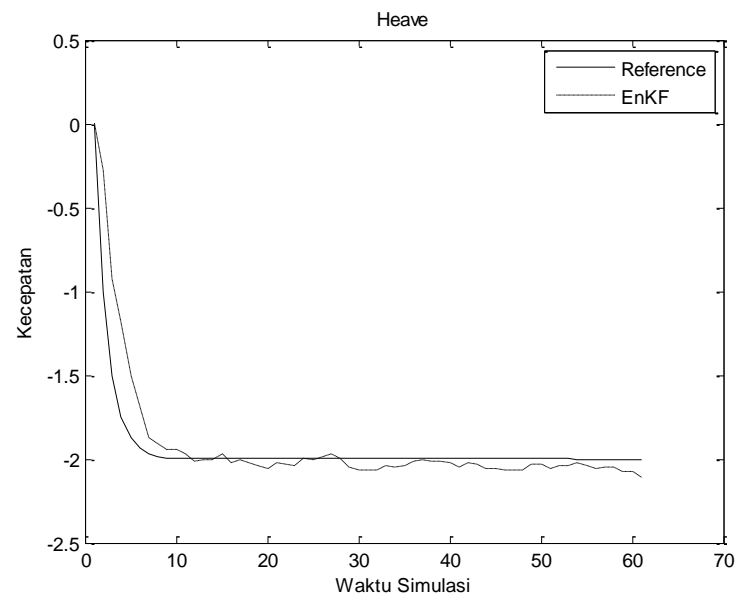

Gambar 3. Estimasi gerak Heave dengan membangkitkan 300 Ensemble

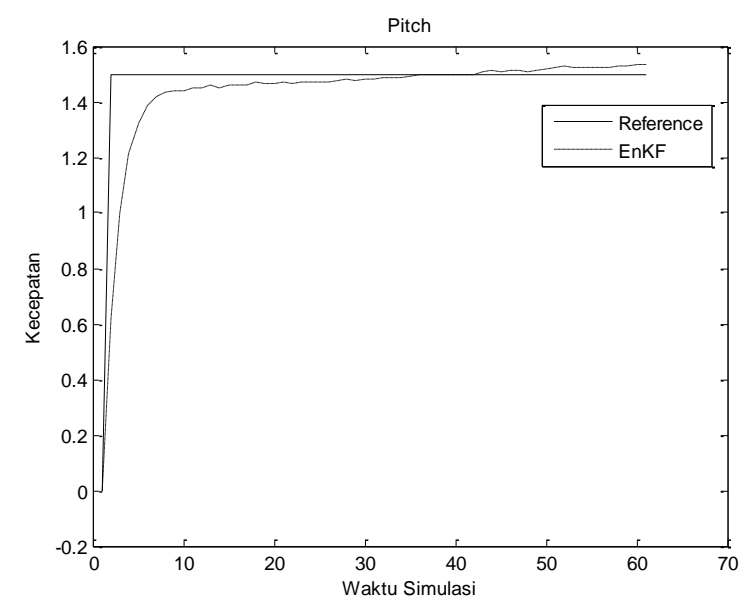

Gambar 4. Estimasi gerak Pitch dengan membangkitkan 300 Ensemble

Gambar 2 sampai Gambar 4 menunjukkan bahwa implementasi metode EnKF pada persamaan gerak menyelam dengan model gerak 3-DOF dengan membangkitkan 300 ensemble memiliki error kecepatan yang cukup kecil, dimana error gerak surge, heave dan pitch memiliki ratarata akurasi $95 \%$ dan error posisi menyelam sekitar 99\%. Pada Gambar 2, tampak bahwa estimasi gerak surge memiliki error kecepatan $0.011241 \mathrm{~m} / \mathrm{s}$ dengan tingkat akurasi $99 \%$. Gambar 3 menunjukkan bahwa error yang dihasilkan pada gerak heave cukup kecil meskipun ada sedikit jarak dengan referencenya dengan tingkat akurasi sekitar 96\%. Gambar 4 merepresentasikan hasil estimasi gerak Pitch yang memiliki error yang cukup kecil sekitar 5\% dengan error kecepatan sudut $0.0042079 \mathrm{rad} / \mathrm{s}$ dengan akurasi 95 \%. Namun pada Gambar 5 ditinjau dari hasil estimasi posisi menyelam, terlihat bahwa error posisi sangat kecil sekitar 0.1\%, dengan tingkat error $99,9 \%$

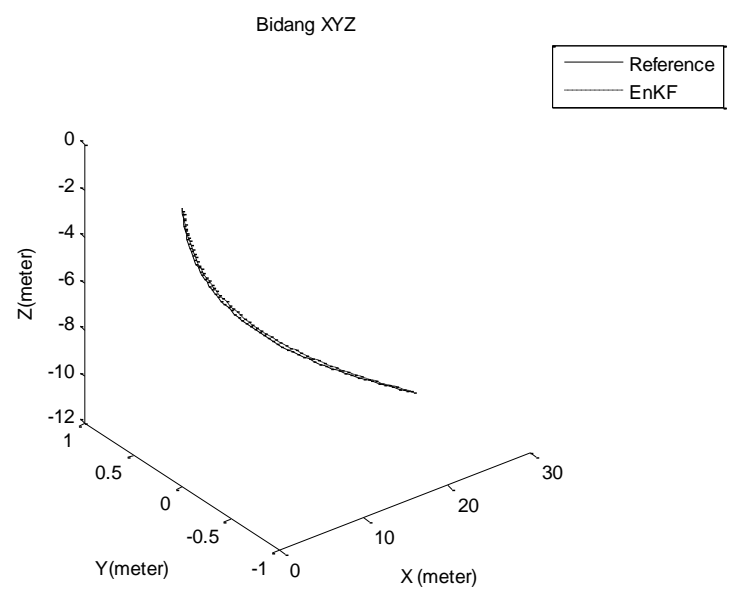

Gambar 5. Estimasi Lintasan Menyelam dengan membangkitkan 300 Ensemble

Tabel 2. Perbandingan Nilai RMSE Hasil Simulasi

\begin{tabular}{|c|c|c|}
\hline \multirow{2}{*}{} & \multicolumn{2}{|c|}{ Berdasarkan Jumlah Ensemble } \\
\cline { 2 - 3 } & $\mathbf{2 0 0}$ & $\mathbf{3 0 0}$ \\
\hline Surge & $0.012546 \mathrm{~m} / \mathrm{s}$ & $0.011241 \mathrm{~m} / \mathrm{s}$ \\
Heave & $0.01378 \mathrm{~m} / \mathrm{s}$ & $0.0092821 \mathrm{~m} / \mathrm{s}$ \\
Pitch & $0.00518 \mathrm{rad} / \mathrm{s}$ & $0.0042079 \mathrm{rad} / \mathrm{s}$ \\
\hline Posisi Menyelam & $0.02371 \mathrm{~m}$ & $0.01056 \mathrm{~m}$ \\
\hline Time Simulation & $4.512 \mathrm{~s}$ & $4.739 \mathrm{~s}$ \\
\hline
\end{tabular}

Selanjutnya perbandingan hasil estimasi dengan membangkitkan 200 dan 300 ensemble pada Tabel 2 menunjukkan bahwa dengan membangkitkan 300 ensemble lebih akurat daripada 200 ensemble. Jika ditinjau dari waktu simulasi bahwa terlihat dengan membangkitkan 300 ensemble memiliki waktu lebih lambat daripada 200 ensemble karena jumlah ensemble yang dibangkitkan lebih besar.

Dari hasil analisa pada simulasi dengan membangkitkan 200 dan 300 ensemble didapatkan memiliki error kecepatan yang kurang dari 5\%, sedangkan untuk error posisi kurang dari 1\% sehingga metode EnKF dapat digunakan sebagai salah satu metode estimasi kecepatan gerak Autonomous Underwater Vehicle (AUV). 


\section{PENUTUP}

Berdasarkan hasil analisa simulasi Ensemble Kalman Filter (EnKF) pada model gerak menyelam 3-DOF (surge, heave dan pitch) pada AUV didapatkan bahwa estimasi gerak menyelam memiliki tingkat akurasi yang cukup tinggi sekitar 95-98\% dengan error kecepatan kurang lebih 5\%. Selain itu error posisi menyelam juga kecil sekitar $0.1 \%$ dengan tingkat akurasi 99\%, Sehingga metode EnKF dapat digunakan sebagai estimator dari gerak translasi Autonomous Underwater Vehicle (AUV).

\section{UCAPAN TERIMA KASIH}

Penulis mengucapkan Terima Kasih Kementerian Riset, Teknologi dan Pendidikan Tinggi (Kemenristekdikti) yang telah mendukung penelitian penulis pada tahun 2019 dengan nomer kontrak 061/SP2H/LT/MONO/L7/2019. Peneliti juga mengucapkan Terima Kasih kepada Pusat Unggulan Mechatronics Indutri Automation (PUI-MIA-RC ITS) dan Laboratorium Robotika ITS.

\section{DAFTAR PUSTAKA}

Ermayanti, Z., Apriliani, E., Nurhadi, H., \& Herlambang, T. (2016). Estimate and control position autonomous Underwater Vehicle based on determined trajectory using Fuzzy Kalman Filter method. ICAMIMIA 2015 International Conference on Advanced Mechatronics, Intelligent Manufacture, and Industrial Automation, Proceeding - In Conjunction with Industrial Mechatronics and Automation Exhibition, IMAE. https://doi.org/10.1109/ICAMIMIA.2015.75 08022

Herlambang, T., Djatmiko, E. B., \& Nurhadi, H. (2015). Ensemble kalman filter with a square root scheme (EnKF-SR) for trajectory estimation of AUV SEGOROGENI ITS. International Review of Mechanical Engineering, $9(6)$. https://doi.org/10.15866/ireme.v9i6.6341

Herlambang, T., Djatmiko, E. B., \& Nurhadi, H. (2016). Navigation and guidance control system of AUV with trajectory estimation of linear modelling. ICAMIMIA 2015 International Conference on Advanced Mechatronics, Intelligent Manufacture, and Industrial Automation, Proceeding - In Conjunction with Industrial Mechatronics and Automation Exhibition, IMAE. https://doi.org/10.1109/ICAMIMIA.2015.75 08028
Herlambang, T., Nurhadi, H., \& Subchan. (2014). Preliminary numerical study on designing navigation and stability control systems for ITS AUV. In Applied Mechanics and Materials (Vol. 493). https://doi.org/10.4028/www.scientific.net /AMM.493.420

Herlambang, Teguh. (2017). Design of a Navigation and Guidance System of Missile with Trajectory Estimation Using Ensemble Kalman Filter Square Root (EnKF-SR ). Computer Applications and Information Processing Technology (CAIPT), 2017 4th International Conference On, 1-7. IEEE.

Herlambang, Teguh, Mufarrikoh, Z., Karya, D. F., \& Rahmalia, D. (2018). Estimation of water level and steam temperature using ensemble Kalman filter square root ( EnKF- SR ) Estimation of water level and steam temperature using ensemble Kalman filter square root ( EnKF-SR ). Journal of Physics: Conference Series, 0-7.

Herlambang, Teguh, \& Nurhadi, H. (n.d.). Position Estimation of ITSUNUSA AUV Based on Determined Trajectory using Kalman Filter ( $K F$ ). 15-22.

Herlambang, Teguh, \& Subchan. (2018). ESTIMASI GERAK TRANSLASI AUTONOMOUS UNDERWATER VEHICLE DENGAN ENSEMBLE KALMAN FILTER (EnKF). Teknika: Engineering and Sains Journal, 2(1), 41-46.

Karya, D. F., Katias, P., \& Herlambang, T. (2018). Stock price estimation using ensemble Kalman Filter square root method Stock price estimation using ensemble Kalman Filter square root method. 0-6.

Loebis, D., Sutton, R., Chudley, J., \& Naeem, W. (2004). Adaptive tuning of a Kalman filter via fuzzy logic for an intelligent AUV navigation system. Control Engineering Practice, 12(12 SPEC. ISS.), 1531-1539. https://doi.org/10.1016/j.conengprac.2003. 11.008

Motwani, A. (2012). Adaptive and interval Kalman filtering techniques in autonomous surface vehicle navigation: a survey.

Oktafianto, K., Herlambang, T., Mardlijah, \& Nurhadi, H. (2016). Design of Autonomous Underwater Vehicle motion control using Sliding Mode Control method. ICAMIMIA 2015 - International Conference on Advanced Mechatronics, Intelligent Manufacture, and Industrial Automation, Proceeding - In Conjunction with Industrial Mechatronics and Automation Exhibition, IMAE. https://doi.org/10.1109/ICAMIMIA.2015.75 08023

Panish, R., \& Taylor, M. (2011). Achieving high 
navigation accuracy using inertial navigation systems in autonomous underwater vehicles. OCEANS 2011 IEEE - Spain, 1-7. https://doi.org/10.1109/Oceans-

Spain.2011.6003517 
T Herlambang, dkk / Teknika : Engineering and Sains Journal, Vol. 3, No.1, Juni 2019, 51-56

Halaman ini sengaja dikosongkan 